\title{
Cancer: the growing monster in Egypt
}

\section{Short communication}

The magnitude of the cancer problem remained unknown until very recently when Egypt national cancer registry program published its results in 2014, after 10years of population-based registration. ${ }^{1}$ The published incidence data replaced the hospital-based proportions that wouldn't help to estimate magnitude of the problem. ${ }^{2}$ The estimated crude incidence of cancer for 2013 was 115.7/100,000 males and 110.3/100,000 females. The estimated incident cases were 114,985 in 2013. Assuming that the age specific incidence rates would not change up to 2050; the number of incident cases would increase to 341,169 due to population growth by $160 \%$ and aging of the population as shown in the corresponding population pyramids. The main cause of increase was attributed to demographic change rather than population growth. This 3 -fold increase varied by site of tumor as shown in the table above. For the most common sites, increase in prostate cancer was highest for prostate cancer (424\%) and lowest for breast cancer (253\%). This expected increase by site would be reflected on control activities for early detection of breast and other cancers. Control of $\mathrm{HCV}$ infection would affect liver cancer. ${ }^{3}$ Plans of control of HCV aim at eradication of the infection that would start to be effective by 2018. Interestingly, childhood cancer would increase to $120 \%$; giving chance for proper planning for equity of distribution of services that are currently mainly located in Cairo (Figures 1-7).

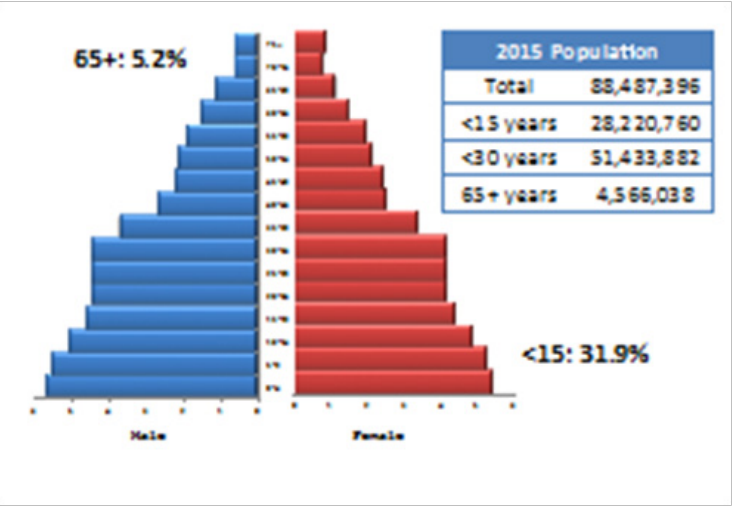

Figure I Demographic background of cancer in Egypt.

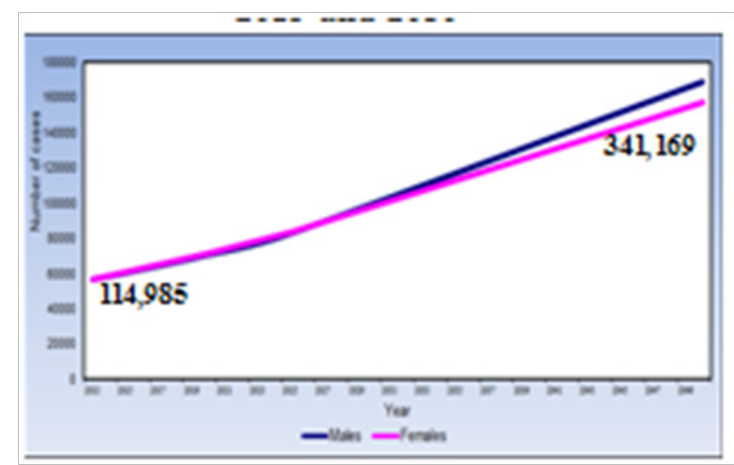

Figure 2 Estimated incident cancer cu0 ases.
Volume 6 Issue 4 - 2016

\author{
Amal S Ibrahim,' Nabiel Nazmi' \\ 'National Cancer Institute, Egypt \\ ${ }^{2}$ Department of Biostatistics and Cancer Epidemiology, South \\ Egypt Cancer Institute, Egypt
}

Correspondence: Amal S. Ibrahim, MD, Dr. PH, Professor of Epidemiology, National Cancer Institute, Cairo University, Director, National Cancer registry program, Egypt, Emailibrahimamalsamy@gmail.com

Received: August 07, 2016 | Published: December 22, 2016

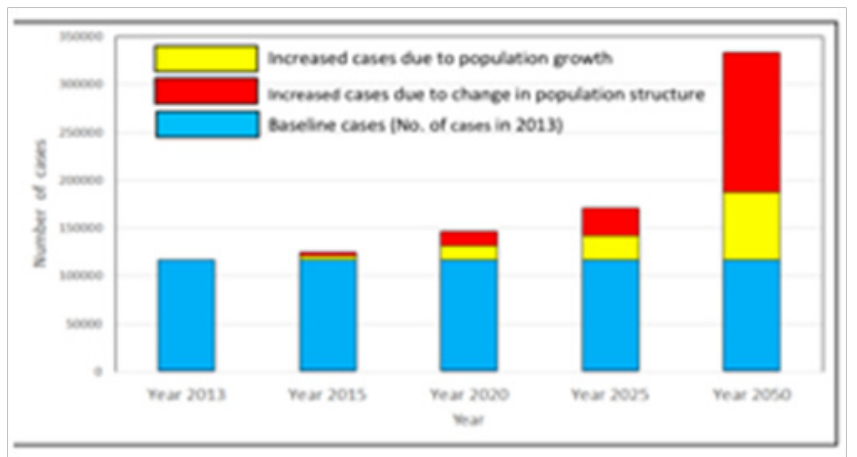

Figure 3 Estimated number of cases in Egypt (2013-2050) and causes of the increase in cases.

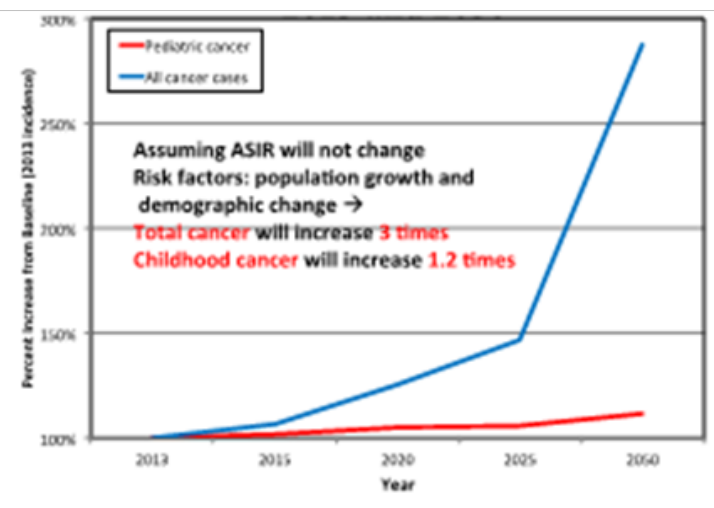

Figure 4 Percentage increase in incident cancer cases 2013 and 2050. 


\section{Increase in frequent cancer sites in 2050 relative to 2015}

- Population

1.60

- All Cancers

- Prostate

- Bladder

- Lung

- Liver

- Brain

- Non-Hodgkin lymphoma

- Breast
Figure $\mathbf{5}$ Increase infrequent cancer sites in 2050 relative to 2015 .

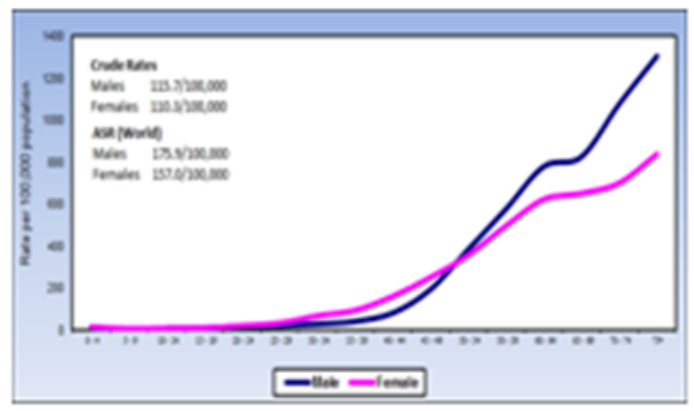

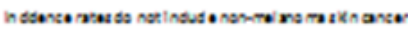

Figure 6 Age-specific incidence rate/I00000 populations.

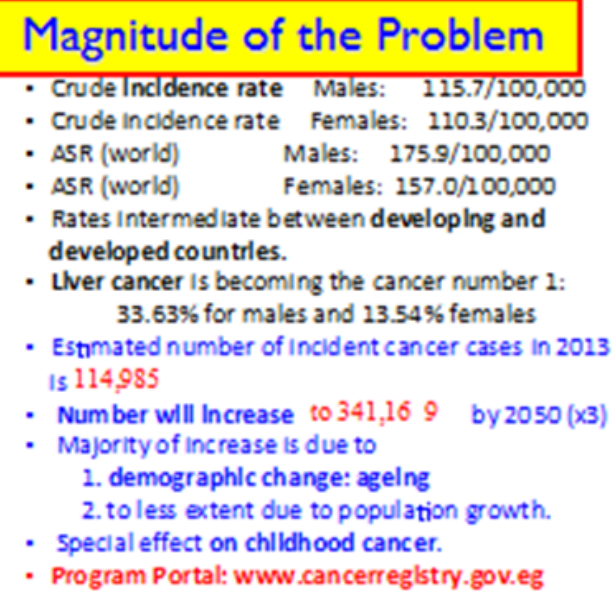

Figure 7 Magnitude of the problem.

\section{Acknowledgments}

None.

\section{Conflicts of interest}

Authors declare there are no conflicts of interest.

\section{References}

1. Ibrahim AS, Khaled HM, Mikhail NN, et al. Cancer incidence in egypt: results of the national population-based cancer registry program. $J$ Cancer Epidemiol. 2014;2014:437971.

2. Ibrahim AS, Mikhail NNH. The Evolution of Cancer Registration in Egypt: From Proportions to Population-based Incidence Rates. SECI Oncology. 2015;2015:4

3. Ezzat S, Abdel-Hamid M, Eissa SA, et al. Associations of pesticides, $\mathrm{HCV}, \mathrm{HBV}$, and hepatocellular carcinoma in Egypt. Int J Hyg Environ Health. 2005;208(5):329-339. 